\title{
Editorial: Drugs in Sport: A Philosophical Challenge
}

There is certainly a strong feeling against the use of drugs in sport, even though many sportsmen and women use them and many more undoubtedly would if they thought they could get away with it. In face of what actually goes on in far too many locker rooms, the efforts of sports authorities to stem the use of drugs can seem futile as well as all too often petty and misguided in practice.

In view of the mess and confusion surrounding the subject it is not surprising to hear apparently cogent arguments mounted against the attempt to rid sports of drug use. It happens anyway, we hear, and better to have it in the open than in secret with all the potential for corruption, blackmail and ill-supervised side-effects. In any case, what is wrong with using drugs to enhance performance? It cannot be that they are artificial aids, because there is a sense in which all fitness regimes and body-building programmes are also artificial in that they produce results which would not have occurred naturally. It would be hard to claim that the bulking-up many athletes go in for through exercise regimes is not artificial, and not potentially harmful either. Moreover, there is an arbitrariness about the banning of some chemical substances (steroids) and not others (creatine). And if there is a future danger in the use of drugs (as some suspect may have been the case in the early death of Flo-Jo), there are plenty of rugby and football players crippled in early middle age as a result of the things they put their bodies through in order to prepare themselves quite naturally for their chosen sport.

In short, people are always going to do all kinds of things to enhance sporting performance, as they have done from the time of the ancient Olympics onwards. Drugs are just one category of many artificial aids, and, looked at objectively, no different in principle from the others. None of these aids will help except at the margins, and except on the basis of great native talent and great dedication, which even with the help of drugs will continue to be vital for the success all crave. So why ban just one set of aids (drugs) and not others (pumping iron), especially when banning itself produces all kinds of deleterious side-effects?

An argument of this sort is philosophically interesting because it exactly parallels so many others in the philosophical literature on a 


\section{Editorial: Drugs in Sport: A Philosophical Challenge}

whole host of ethical and political issues. $\mathrm{X}$ is banned, but this is a prejudice because $\mathrm{X}$ is no different or only very slightly different from $\mathrm{Y}$, which is not; banning $\mathrm{X}$ will not work, because people will do X anyway; and attempting to impose the ban has bad effects in itself, which would not occur were X-ing all regulated and above board. Defenders of the banning of $\mathrm{X}$ seem to be left in the position of protesting rather feebly against the crossing of boundaries, feebly because their opponents will say that the boundary has already been crossed.

Yet - to return to the real world from one's philosophical seminar room - do not most of us feel that there would be something tarnished and corrupt about a sport where ultimate success depends on the use of drugs? Is there not a tinge of special pleading about calling dedicated fitness training artificial in the same way as injecting extra testosterone? Is there not something intellectually and morally lazy about not defending a prohibition just because it is hard to enforce and fuzzy at the edges? And is there not something right about the deep-rooted intuition that the achievement of even the most highly coached and fanatically fit athlete is real in a way a drug induced performance is not, an intuition which led to almost universal sadness when it emerged that what had looked like an amazing and inspiring performance from Ben Johnson in the 1988 Olympics was nothing of the sort?

The philosophical challenge is not to produce a pro-drugs argument. The real challenge is to articulate and elaborate the anti-drugs case so as to reveal the pro-drugs arguments for the sophistries they are. 